\title{
Correction to: The high energy emission of the Crab's twin pulsar PSR J0540-6919 in the Large Magellanic Cloud
}

\author{
G. Machabeli ${ }^{1} \cdot$ A. Rogava $^{1} \cdot$ N. Chkheidze ${ }^{1} \cdot$ N. Kevlishvili $^{1}$
}

Published online: 20 May 2019

(c) Springer Nature B.V. 2019

Correction to: Astrophys Space Sci (2019) 364:71

https://doi.org/10.1007/s10509-019-3562-8

The third author's name is incorrectly spelled in the original article. It is spelled correctly here.

Publisher's Note Springer Nature remains neutral with regard to jurisdictional claims in published maps and institutional affiliations.

The online version of the original article can be found under https://doi.org/10.1007/s10509-019-3562-8.

$凶$ G. Machabeli

g.machabeli@iliauni.edu.ge

1 Centre for Theoretical Astrophysics, ITP, Ilia State University, G. Tsereteli 3, Tbilisi 0162, Georgia 